\title{
Characteristics of tuberculosis contact of children with pulmonary tuberculosis
}

\author{
Magdalena Sidhartani, Retno Murti Laila
}

\begin{abstract}
Background Children with tuberculosis (TB) are often asymptomatic, so that if TB is diagnosed in a child, an adult contact should be looked for. We realize the importance of TB control by breaking the chain of transmission, so identification of contact and prompt treatment should be made.

Objective To trace contact of children with pulmonary tuberculosis (PTB) and to determine the environmental characteristics associated with TB transmission.

Methods Prospective, community based descriptive study was done in 80 children with newly diagnosed PTB treated at Pediatric Pulmonary Ward, Kariadi Hospital, from September 2003 to February 2004. Clinical condition, chest x-ray (CXR), acid fast bacilli (AFB) staining of sputum, and environmental characteristics of adults suspected as TB contact were examined. Data were analyzed by uni- and bivariate analysis using SPSS 11.5.
\end{abstract}

Results Eighty adults with suspected TB were enrolled, 90\% were household contacts. There were $63(79 \%)$ confirmed TB contacts in rural and urban area. Fathers were predominates $(32 \%)$ followed by grandparents (26.3\%), relatives (18.7\%), and mothers (12.5\%). There was no significant difference about internal (household) and external (non-household) family contacts between rural and urban area $(\mathrm{P}=1.000)$. In urban area, home transmission is more frequent than rural area $(P=0.340)$. In urban area, the contacts had a better perception but had no better attitude toward treatment, although the difference was not significant. Behavior was worsen in rural area $(P=0.214)$. Poor behavior seldom occurred in those who had enough knowledge of TB, although the difference was not statistically significant $(P=0.352)$. In the urban area, the house of contacts had lower sleeping density $(P=0.282)$, poor ventilation $(P=0.306)$, and higher room temperature $(P=0.683)$. There were no differences in the light intensity and humidity.

Conclusion There were $79 \%$ confirmed TB contacts in rural and urban area with male predominant. There was no significant difference between household and non-household contacts in rural and urban area. There are different characteristics, such as knowledge, perception, attitude towards treatment, and behavior associated with TB transmission between contacts in the rural and urban area, and between lower, middle, and higher socio- economic level, although the difference is not significant [Paediatr Indones 2006;46:250-254].

Keywords: tuberculosis, contact, environmental characteristic, spitting habit, open crush

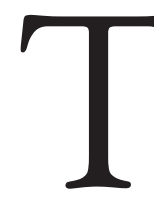

uberculosis (TB) remains a global threat to health for decades, and is one of 10 main causes of death in the developing countries, comprises $95 \%$ of TB cases in the world. Data from the Indonesian Household Health Survey showed that TB ranked third among the cause of death of all age group and ranked first among infectious diseases. ${ }^{1}$

Children with TB are often asymptomatic, so if TB was diagnosed in a child, an adult contact should be looked for. Data from the Pediatric Pulmonary Clinic, Kariadi Hospital, Semarang, showed that the occurrence of TB patients were constant, 94.35\% from 30,465 patients from the year of 2000-2002.

Presented at The $13^{\text {th }}$ National Child Health Congress, Bandung, Indonesia, 4-7 Juli 2005.

From the Department of Child Health, Medical School, Diponegoro University, Semarang, Indonesia.

Reprint request to: Magdalena Sidhartani, MD, Department of Child Health, Diponegoro University, Kariadi Hospital, Jl. Dr. Sutomo 18, Semarang, Indonesia. Tel/Fax. 62-24-8414296. Email: magda_sid@yahoo.com. 
During the first 3 months in 2003, new TB cases were diagnosed in 78 children, which only 28 contacts were ascertained. ${ }^{2}$

We realize the importance of TB control by breaking the chain of transmission, so identification of contact and prompt treatment should be made. This study was conducted to trace contact of children with pulmonary tuberculosis (PTB) and determine the environmental characteristics associated with TB transmission.

\section{Methods}

A prospective study was performed on children diagnosed as PTB in the Pediatric Pulmonary Clinic, Kariadi Hospital, from September 2003 until February 2004. The diagnosis was based on at least 3 of the following criteria: 1) positive tuberculine skin test (TST), 2) contact with an infected subject, 3) chest $\mathrm{x}$-ray (CXR) findings suggesting $\mathrm{TB}, 4)$ lymphadenopathy, 5) failure to gain weight or decline in weight despite nutritional intervention, 6) prolonged fever, night sweats, and 7) history of cough for more than 3 weeks. The children with PTB were treated by 6 months-course of daily isoniazid, rifampicin, pyrazinamid for 2 months followed by 4 months isoniazid and rifampicin daily with Directly Treatment Short Course (DOTS) strategy. As soon as PTB was diagnosed, we approached the parents. The parents or other suspected contacts who lived within the same house were invited to participate in the study. Before the study begun, permission was obtained from the office of Semarang municipality (from Badan Kesatuan Bangsa dan Perlindungan Masyarakat). After informed consent was obtained, home visit was conducted to make a direct observation of their home and environmental characteristics, such as housing quality and living area. Interview were made to obtain information on education, knowledge, perception about TB, habit, socio-economic conditions related to father's occupation, and family income. We used a standardized questionnaire that had been tested for its reliability and validity in 2002 by Kuswantoro ${ }^{3}$ in 3 TB clinics in Central Java. If parents or adults in the same house had symptoms suggesting TB such as low grade fever, chronic cough, lymphadenopathy, they were further referred to a local TB clinic (Balai Pemberantasan dan Pengobatan Penyakit Paru) and underwent physical examination, CXR, and sputum smear for acid fast bacilli (AFB). If they were diagnosed as PTB, they were treated according to the Ministry of Health policy using 4 drug regimens, i.e. daily isoniazid, rifampicin, pyrazinamide, and ethambutol for 2 months followed by isoniazid and rifampicin for 4 months. Follow-up and evaluations were made after completion of treatment.

Those in the household that were not diagnosed as PTB were given health education and advised to come to a doctor, health center or a local TB clinic whenever they have suggestive symptoms of TB. The data were analyzed using SPSS 11.5.

\section{Results}

Eighty adults in the household were suspected as contact of 80 newly diagnosed PTB children, based on the symptoms of TB. They lived in Semarang district, $83 \%$ were in urban and peri-urban area. Out of 80 suspects, $79 \%$ of them were confirmed TB based on positive AFB in the sputum smear and/ or positive CXR for TB, such as hilar or mediastinal lymphadenopathy, opacities or cavitation.

Table 1 shows the characteristics of 80 children with newly diagnosed PTB, and the source of infec-

Table 1. Characteristics of PTB children

\begin{tabular}{|c|c|c|}
\hline Characteristic & Frequency & Percentage (\%) \\
\hline \multicolumn{3}{|c|}{ Socio economic status } \\
\hline Low & 23 & 29 \\
\hline Middle & 37 & 47 \\
\hline High & 20 & 25 \\
\hline \multicolumn{3}{|l|}{ Sleeping density } \\
\hline$<0.5$ & 22 & 28 \\
\hline $0.5-0.7$ & 6 & 7 \\
\hline$>0.7$ & 52 & 65 \\
\hline \multicolumn{3}{|l|}{ Ventilation } \\
\hline$<10 \%$ & 58 & 72 \\
\hline$\geq 10 \%$ & 22 & 28 \\
\hline \multicolumn{3}{|l|}{ Light intensity } \\
\hline$<60$ lux & 0 & 0 \\
\hline$\geq 60$ lux & 80 & 100 \\
\hline \multicolumn{3}{|c|}{ Room temperature } \\
\hline$<18^{\circ} \mathrm{C}$ & 0 & 0 \\
\hline $18-30^{\circ} \mathrm{C}$ & 30 & 38 \\
\hline$>30^{\circ} \mathrm{C}$ & 50 & 62 \\
\hline \multicolumn{3}{|l|}{ Humidity } \\
\hline$<40 \%$ & 0 & 0 \\
\hline $40-70 \%$ & 32 & 40 \\
\hline$>70 \%$ & 48 & 60 \\
\hline \multicolumn{3}{|c|}{ Degree of relatedness } \\
\hline Father & 25 & 32 \\
\hline Grandparents & 21 & 26 \\
\hline Relatives & 15 & 19 \\
\hline Mother & 10 & 13 \\
\hline Neighbor & 9 & 11 \\
\hline
\end{tabular}


tion was determined by history and interview, before ascertainment of AFB sputum staining and CXR were done. It showed that the source of infection was predominantly internal (household) of $89 \%$, while external (non household) was only $11 \%$.

Children with PTB lived in a crowded room, high room temperature, and humidity with poor ventilation.

After home visit and interview, it revealed that of 80 persons, 63 were the source of infection, as proved by positive AFB and/or CXR findings. The characteristics of the source of infections are shown in Table 2.

Male predominates, and more than one-third of them only finished primary school make the consequence of working with a low salary and poor housing condition. Although the knowledge was good in average, the perception and behavior was not reflected their knowledge.

Table 2. Characteristics of contacts

\begin{tabular}{lcc}
\hline \multicolumn{1}{c}{ Characteristic } & Frequency & Percentage (\%) \\
\hline Sex & & \\
$\quad$ Male & 40 & 63 \\
$\quad$ Female & 23 & 37 \\
Education & & \\
$\quad$ Illiterate & 2 & 3 \\
$\quad$ Primary school & 23 & 37 \\
$\quad$ Junior high school & 9 & 14 \\
$\quad$ Senior high school & 22 & 35 \\
$\quad$ University & 7 & 11 \\
Socio economic status & & \\
$\quad$ Low & 21 & 33 \\
$\quad$ Middle & 24 & 38 \\
$\quad$ High & 18 & 29 \\
Knowledge & & \\
$\quad$ Good & 39 & 62 \\
$\quad$ Bad & 24 & 38 \\
Perception & & \\
$\quad$ Aware & 26 & 41 \\
$\quad$ Unaware & 37 & 59 \\
Behavior & & \\
$\quad$ Treated & 17 & 27 \\
$\quad$ Not treated & 46 & 73 \\
\hline
\end{tabular}

Table 3 shows the environment of the contact. It reflects closed relationship of their living conditions with the diseases. More than $80 \%$ of their houses were in the peri-urban and urban area, in which they often live in shanty condition with poor ventilation and high sleeping density. Those condition enhaced disease's transmission.

If we look at the positive TB contact, 52 (83\%) lived in the urban or peri-urban area. The most
Table 3. Characteristics of place of contacts

\begin{tabular}{|c|c|c|}
\hline Characteristic & Frequency & Percentage (\%) \\
\hline \multicolumn{3}{|l|}{ Location } \\
\hline Rural & 11 & 18 \\
\hline Peri-urban & 45 & 71 \\
\hline Urban & 7 & 11 \\
\hline \multicolumn{3}{|l|}{ Sleeping density } \\
\hline$<0.5$ & 22 & 35 \\
\hline $0.5-0.7$ & 6 & 10 \\
\hline$>0.7$ & 35 & 55 \\
\hline \multicolumn{3}{|l|}{ Ventilation } \\
\hline$<0 \%$ & 40 & 63 \\
\hline$\geq 10 \%$ & 23 & 37 \\
\hline \multicolumn{3}{|l|}{ Light intensity } \\
\hline$<60$ lux & 2 & 3 \\
\hline$\geq 60$ lux & 61 & 97 \\
\hline \multicolumn{3}{|l|}{ Room temperature } \\
\hline $18-30^{\circ}$ & 28 & 44 \\
\hline$>30^{\circ} \mathrm{C}$ & 35 & 56 \\
\hline \multicolumn{3}{|l|}{ Humidity } \\
\hline $40-70 \%$ & 28 & 40 \\
\hline$>70 \%$ & 35 & 60 \\
\hline \multicolumn{3}{|l|}{ Spitting } \\
\hline Yes & 52 & 82 \\
\hline No & 11 & 18 \\
\hline \multicolumn{3}{|l|}{ "Protected cough" } \\
\hline Yes & 13 & 21 \\
\hline No & 50 & 79 \\
\hline
\end{tabular}

likely place of contact was in their house, where the children spent most of their time, making an intimate contact, and enhanced the disease by the open cough and bad spitting habit.

Table 4 shows confirmed contact in relation with case, and place of contact.

Table 6 shows that in the urban area sleeping density was less than that in rural, but poorer ventilation. Daylight time was the same both in the urban or rural area. There was no significant difference in all variables between urban and rural area.

Table 4. Confirmed contact in Relation With Case and PLACE OF CONTACT

\begin{tabular}{|c|c|c|c|c|c|}
\hline \multirow[t]{2}{*}{ No. } & \multirow[t]{2}{*}{ Characteristic } & \multicolumn{3}{|c|}{ Location } & \multirow[t]{2}{*}{$x^{2}$-test } \\
\hline & & Rural & Urban & Total & \\
\hline \multirow{2}{*}{1.} & Positive & 11 & 52 & 63 & $P=0.827$ \\
\hline & Negative & 4 & 13 & 17 & \\
\hline \multirow[t]{3}{*}{2.} & Relation & & & & \\
\hline & Family & 12 & 52 & 64 & $P=1.000$ \\
\hline & Non family & 3 & 13 & 16 & \\
\hline \multirow[t]{3}{*}{3.} & Place of contact & & & & \\
\hline & Internal & 12 & 60 & 72 & $P=0.340$ \\
\hline & External & 3 & 5 & 8 & \\
\hline
\end{tabular}


Magdalena Sidhartani et al: Tuberculosis contact of children with pulmonary tuberculosis

TABle 5. KNowledge, PeRCEPtion AND BeHAVIOR of CONTACT

\begin{tabular}{|c|c|c|c|c|c|}
\hline \multirow[t]{2}{*}{ No. } & \multirow[t]{2}{*}{ Characteristic } & \multicolumn{3}{|c|}{ Location } & \multirow[t]{2}{*}{$x^{2}$-test } \\
\hline & & Rural & Urban & Total & \\
\hline \multirow[t]{3}{*}{1.} & TB knowledges & & & & \\
\hline & Good & 4 & 35 & 39 & $P=0.114$ \\
\hline & Poor & 7 & 17 & 24 & \\
\hline \multirow[t]{3}{*}{2.} & Perception & & & & \\
\hline & Aware & 4 & 22 & 26 & $P=0.979$ \\
\hline & Unaware & 7 & 30 & 37 & \\
\hline \multirow[t]{3}{*}{3.} & Behaviour & & & & \\
\hline & Treated & 5 & 12 & 17 & $P=0.129$ \\
\hline & Not treated & 6 & 40 & 46 & \\
\hline \multirow[t]{3}{*}{4.} & Spitting & & & & \\
\hline & Yes & 11 & 41 & 52 & $P=0.214$ \\
\hline & No & 0 & 11 & 11 & \\
\hline \multirow[t]{3}{*}{5.} & Protected cough & & & & \\
\hline & Yes & 1 & 12 & 13 & $P=0.528$ \\
\hline & No & 10 & 40 & 50 & \\
\hline
\end{tabular}

Table 6. Housing condition according to location

\begin{tabular}{|c|c|c|c|c|c|}
\hline \multirow[t]{2}{*}{ No. } & \multirow[t]{2}{*}{ Characteristic } & \multicolumn{3}{|c|}{ Location } & \multirow[t]{2}{*}{$x^{2}$-test } \\
\hline & & Rural & Urban & Total & \\
\hline \multirow{3}{*}{1.} & Sleeping density & & & & \\
\hline & High & 7 & 21 & 28 & $P=0.282$ \\
\hline & Low & 4 & 31 & 35 & \\
\hline \multirow[t]{3}{*}{2.} & Ventilation & & & & \\
\hline & Poor & 5 & 35 & 40 & $P=0.306$ \\
\hline & Good & 6 & 17 & 23 & \\
\hline \multirow[t]{3}{*}{3.} & Daylight & & & & \\
\hline & Poor & 0 & 2 & 2 & $P=1.000$ \\
\hline & Good & 11 & 50 & 61 & \\
\hline \multirow[t]{3}{*}{4.} & Humidity & & & & \\
\hline & Low & 4 & 21 & 25 & $P=1.000$ \\
\hline & High & 7 & 31 & 38 & \\
\hline \multirow[t]{3}{*}{5.} & Temperature & & & & \\
\hline & Low & 6 & 22 & 28 & $P=0.683$ \\
\hline & High & 5 & 30 & 35 & \\
\hline
\end{tabular}

\section{Discussion}

The results showed that the most prominent contacts were male. From 80 suspected contacts, fathers ranked first, but surprisingly the mother was only ranked fourth. After establishing the diagnosis of TB from all suspects, it appeared that $45 \%$ of them was their parents, with male predominant. This finding confirmed the study of Caldeira that father and mother were equally known as sources of infection and she found that $66.5 \%$ of them were parents. ${ }^{4}$

Contact with confirmed positive TB was 79\% in our study and $89 \%$ of the source of infection were in the household. This is similar with Caldeira's findings ${ }^{4}$ which were $92.4 \%$ but it is higher than $\operatorname{Lin}^{5}(50 \%)$ and Lobato ${ }^{6}$ (63\%). This discrepancy may be due to population and design study differences. Ours was a prospective community based study, while Caldeira ${ }^{4}$ did a prospective study in Municipal Health Care Center, Rio de Janeiro Brazil. Lin $^{5}$ did a retrospective hospital based study in North Taiwan, and Lobato ${ }^{6} \mathrm{did}$ a retrospective study in a referral hospital in San Francisco and 2 health jurisdiction in California.

Concerning the contact location, there were $83 \%$ of contacts located in urban and peri-urban area, mostly in the internal environment or household, with low sleeping density, but poor ventilation, higher room temperature, and humidity. The contact had frequent spitting habits $(83 \%)$ and open cough $(80 \%)$. This emphasized that unhygienic behavior enhanced TB transmission. Several contributing factors for transmission include inadequate ventilation, overcrowding, presence of an open or unprotected, forceful cough, and high-volume respiratory secretions. The most important determinant is the presence of AFB in the sputum, or positive sputum culture, presence of lung cavitation, and inadequate treatment of PTB. ${ }^{7}$ There was more contact living in the urban area with better knowledge and perception about TB. However, this did not reflect the willingness to get treatment.

Low socio-economic status leads to poor access or compliance causing unsuccessful or failure of treatment. Bad or unhealthy behavior may be due to low income, but other factors may play a role, such as subjective norm or behavioral intention. Level of education in this study did not reflect their knowledge about TB since access to information is widely open this day. These were similar with that of Perry and Starke ${ }^{8}$ studied that low income, overcrowding and poor living standard favors TB transmission. Sustained contact and inadequate ventilation also give a contribution. In the present study, $88 \%$ were household contact. This confirmed a study by Beyers 9 which highlighted the importance of contact proximity to the risk of infection.

We concluded that among $79 \%$ positive TB cases, 45\% TB contacts were parents. This confirmed that living in the same household put at higher risk than casual contact. We found no significant difference in family contact between those living in the rural and urban. There were differences between rural and urban, and between lower and middle-high socio economic in the characteristics of knowledge, perception, attitude toward treatment and behavior associated with 
transmission although statistically not significant. Contact tracing is important for TB control, and may promote the reduction of child TB-related morbidity and mortality.

\section{References}

1. Manaf A. Program tuberkulosis paru. Dalam: Simposium Respirologi Anak Masa Kini. Bandung: IDAI Jawa BaratUKK Pulmonologi-IKA FK UNPAD/RSHS, 1998:1-9.

2. Register Harian Poli Paru Anak RS Dr. Kariadi Semarang, 2000-2002.

3. Kuswantoro. Faktor-faktor yang berhubungan dengan kejadian TB paru primer pada anak balita di BP4 Purwokerto [thesis]. Semarang. Program Magister FKM-Undip,2002.

4. Caldeira Z MR, Sant'Anna CC, and Aide MA. Tuberculosis contact tracing among children and adolescents, Brazil. Rev Saude Publica 2004;38(3): 339-45.
5. LinYS, Huang YC, Chang LY, Lin TY and Wong KS. Clinical characteristics of tuberculosis in children in the north of Taiwan. Microbiol Immunol Infect 2005;38:41-6.

6. Lobato MN, Loeffler AM, Furst K, Cole B, Hopewell PC. Detection of Mycobacterium tuberculosis in gastric aspirates collected from children: Hospitalization is not necessary. Pediatrics 1998;102:40.

7. Askew GL, Finelli L, Hutton M, Laraque F, Porterfield D, Shilkret K, et al. Mycobacterium tuberculosis transmission from a pediatrician to patients. Pediatrics 1997;100:19-23.

8. Perry S, Starke JR. Adherence to prescribed treatment and public health aspects of tuberculosis in children. Semin Pediatr Inf Dis 1993;4:291-8.

9. Beyers N, Gie RP, Schaaf HS, Van Zyl S, Talent JM, Nel ED, et al. A prospective evaluation of children under the age of 5 years living in the same household as adults with recently diagnosed pulmonary tuberculosis. Int J Tuberc Lung Dis 1997;1:38-43. 